\title{
Bularreko minbizia jasan duten eta linfedema pairatzen duten emakumeen bizi-kalitatea: erizaintza-zainketak
}

\author{
Quality of life in women who suffered breast cancer and develop \\ lymphedema: nursing care \\ Estibaliz Larrañaga Manzano \\ Zarauzko Osasun Zentroa \\ larranagaestibaliz@gmail.com
}

\section{Laburpena}

Sarrera: Minbiziaren aurkako Espainiako Elkartearen datu epidemiologikoen arabera, 2012 eta 2019 urte tartean bularreko minbiziaren intzidentzia \% 7,5 hazi da. Ondorioz, minbiziari aurre egiteko tratamendua jaso duten emakumeen eta horrekin erlazionatutako linfedemaren intzidentziak ere gora egin du. Frogatu da linfedema pairatzen dutenek ezintasun handiagoa dutela, bizi-kalitate okerragoa eta nahasmendu psikologiko gehiago dituztela konplikazio hori ez dutenek baino, eta, ikerketek diotenaren arabera, erizaintza-zainketek paziente horien egoera hobetu dezakete.

Helburua: Lan honen helburu orokorra da bularreko minbizia jasan duten eta linfedema pairatzen duten emakumeen bizi-kalitatea hobetu dezaketen erizaintza-zainketak aztertzea.

Metodologia: Helburuen garapenerako berrikusketa narratiboa erabili da eta PIO egiturari jarraituta zenbait datu-basetan (Pubmed, Biblioteca Virtual de la Salud, Dialnet, Cuiden eta Cochrane) bilaketa bibliografikoa aurrera eraman da. Horrez gain, informazio zabalagoaren bila, hainbat web-orri ere kontsultatu dira (Asociación Española contra el Cáncer, American Society of Clinical Oncology, National Cancer Institute eta NNNConsult). Barneratze- eta kanporatze-irizpideak aplikatu ondoren, 17 artikulu, txosten zientifiko 1 eta 4 web-orrirekin egin da lan.

Emaitzak: Linfedemak pazientearen bizi-kalitatean eragin nabarmena daukaongizate fisikoan, psikologikoan, sozialean eta espiritualean. Erizain-interbentzioek bizi-kalitatea hobetzen lagundu dezakete identifikazio goiztiarrarekin, osasun-heziketarekin, profesionalen koordinazioarekin, autozainketaren promozioarekin eta konpresio-arropen erabilera bultzatzearekin.

Ondorioak: Linfedemak 7 domeinuetan du eragina pazienteen eguneroko bizitzan.Erizaintzari dagokionez, osasunaren promozioan eta konplikazioaren prebentzioan dago gakoa.

Gako-hitzak: Linfedema, bizi-kalitatea, erizaintza-zainketak

\section{Abstract}

Background: According to the epidemiologic data published by the Spanish Association Against Cancer, breast cancer incidence has increased 7,5 \% between 2012 and 2019. Therefore, so has the number of breast cancer survivors and possible lymphedema developers. It has been proved women who develop lymphedema are more likely to have difficulties, worse quality of life and psychological disorders. 
Purpose: The objective of this study was to determine what nursing care can improve quality of life in women who suffered breast cancer and developed lymphedema.

Methods: A narrative review has been developed following the PIO structure.Different data-bases were consulted (Pubmed, BVS, Dialnet, Cuiden and Cochrane). Besides, for further information some web sites were consulted too. After applying inclusion and exclusion criteria 17 articles, a scientific document and 4 web sites have been used.

Results:Lymphedema has a great impact in patients quality of life affecting physical condition, psychological condition, social condition and spiritual condition. Nursing intervention can help to improve their quality of life with early identification, health education, coordination of sanitary professionals, promotion of health and encouraging the use of comprehensive clothes.

Conclusions:Patients everyday life is affected in seven domains by lymphedema. The keys in nursing are health promotion and prevention.

Keywords: Lymphedema, quality of life, nursing

Bidalia: 2020.07 .06

Onartua: 2021.03.26

http://doi.org/10.26876/osagaiz.1.2021.315

\section{Sarrera}

Bularreko minbizia munduan zehar emakumeen artean izaten den minbizi ohikoena da, minbizien \% 25 en eta horiekin erlazionatutako heriotzen \% 15en erantzulea. 2019. urtean Espainian 33.307 kasu berri diagnostikatu dira, adibidez(AECC, 2019).Tratamendu desberdinak ditu, hala nola ebakuntza, kimioterapia, erradioterapia eta terapia hormonala. Nahiz eta tratamenduok bizi-itxaropena luzatu, bizi-kalitatean eragin negatiboa duten hainbat konplikaziorekin erlazionatzen dira, adibidez, linfedemarekin(Cal A, 2016; De Miguel C, 2017; Nadal MJ, 2015; Stuiver MM, 2015).

Linfedema sistema linfatikoan gertatzen den buxaduraren ondorioz garatzen den likido-pilaketa anormalari deritzo. Likido linfatiko horrek plasma-proteinak, odol-zelula estrabaskularrak, uraren eta parenkimaren produktuak izan ditzake. Nahasmendu kronikoa eta progresiboa da eta prebentzioa eta tratamendu goiztiarra beharrezkoak ditu kontrolpean izateko (Alonso B, 2016) (AECC, 2018; Alonso B, 2016; Bromham N, 2017; NCl, 2019; Stuiver MM, 2015).

Asociación Española Contra el Cáncer (AECC) elkartearen datu epidemiologikoen arabera, 2012 eta 2019 urte tartean bularreko minbiziaren intzidentzia \% 7,5 hazi da (AECC, 2019). Ondorioz, minbiziari aurre egiteko tratamendua jaso duten emakumeen eta horrekin erlazionatutako linfedemaren (linfedema sekundarioa) intzidentziak ere gora egin du. Linfedemaren intzidentzia zehatza ezezaguna izan arren, \% 5-65 tartean aurkitzen da, eta azken urteetako datuen arabera, bularreko minbiziaren aurka egiteko tratamendua jaso duten lau emakumetik batek izaten duen konplikazio garrantzitsua da. Bularreko minbizia diagnostikatu dieten emakumeen \% 20k goiko gorputz-adarreko linfedema garatzea espero da 6 hilabeteren buruan, \% 36k urtebetera eta \% 54k 36 hilabeteetara (Alonso B, 2016).

Zoritxarrez, maiz gutxi ulertu, gutxi aztertu eta erlatiboki gutxietsi egiten den arazoa da. Garrantzitsua da osasun-profesionalentzat ordea, pazienteetan maiz ikusten baita, eta eragin handia baitu haien bizi-kalitatean (AECC, 2018; ASCO, 2020; Alonso B, 2016; Burckhardt M, 2014; Gass J, 2016; $\mathrm{NCl}, 2019$ ).

Bularreko minbizia izan duten emakumeen artean, frogatu da linfedema pairatzen dutenek ezintasun handiagoa dutela, bizi-kalitate okerragoa dutela eta nahasmendu psikologiko gehiago dituztela konplikazio hau ez dutenek baino(ASCO, 2020; Jeffs E, 2015; NCl, 2019; Temur K, 2019). 
Osasunaren Munduko Erakundeak (OME) honela definitzen du bizi-kalitatea: gizabanako bakoitzak bere existentziaganako, kulturaren testuinguruarenganako eta balio-sistemarenganako duen pertzepzioa, bere helburuekin, itxaropenekin, arauekineta egonezinekin erlazioan. Bakoitzaren egoera fisikoaren, psikologikoaren, independentzia-mailaren, erlazio sozialen eta ingurumenarekin duen erlazioaren eraginpean dagoen kontzeptua da(Garcia SN, 2015; OMS, 2019).

Hainbat ikerketak erakutsi dute erizainek garrantzi handia dutela linfedemaren tratamendua jasotzen duten pazienteen ebaluazioan eta kondizio horren prebentzioan. Egoera horretan dauden emakumeen \% 49k linfedemaren inguruan erizainon informazioa eta laguntza jasotzeko beharra erakutsi du. Gainera, frogatu da erizainon heziketa eta aholkuak jasotako pazienteetan linfedema izateko arriskua murrizten dela eta haien bizi-kalitatea hobetzen dela(Burckhardt M, 2014; Cal A, 2016; Jeffs E, 2015; Karlsson K, 2015).

\section{Helburuak}

Lan honen helburua da bularreko minbizia jasan duten eta linfedema pairatzen duten emakumeen bizi-kalitatea hobetu dezaketen erizaintza-zainketak aztertzea.

\section{Metodologia}

Aurretik aipatutako helburuak lortzeko, errebisio narratiboa erabili da. Horretarako, zenbait datubasetan bilaketa egin da 2019ko irailetik 2020ko urtarrilera bitartean eta PIO egitura erabili da (Ikusi 1. taula):

- Patient (pazientea, taldea): Bularreko minbiziaren ondorioz, linfedema pairatzen duten emakumeak.

- Intervention (esku-hartzea): Erizaintza-interbentzioak.

- Outcome (emaitzak): Pazienteak dituen onurak eta bizi-kalitatean hobekuntzak.

PIO egitura kontuan izanik, proposatzen den galdera honakoa da:

"Zein dira linfedema izaten duten emakumeetan eman beharreko erizaintza-arreta?"

1. taula. PIO egituraren arabera bilaketa bibliografikoa aurrera eramateko erabili diren DeCS/MeSH eta gako-hitzen sailkapena.

\begin{tabular}{|c|l|l|l|}
\hline \multicolumn{2}{|c|}{ Gako-hitzak } & \multicolumn{1}{c|}{ DeCS } & \multicolumn{1}{c|}{ MeSH } \\
\hline P & Cáncer de mama & $\begin{array}{l}\text { Neoplasias de la mama } \\
\text { Linfedema }\end{array}$ & $\begin{array}{l}\text { Breast neoplasms } \\
\text { Lymphedema }\end{array}$ \\
\hline I & & Enfermería & Nursing \\
\hline O & & Calidad de vida & Quality of life \\
\hline
\end{tabular}

Iturria: propioa. 
Horrez gain, bilaketa zehatzagoa izan zedin AND operadore boolearra eta hurrengo iragazkiak aplikatu dira:

- Argitalpen-data: 2014-2020

- Hizkuntza: gaztelania, ingelesa

- Emakumeak

Datu-baseei dagokienez, osasun-zientzien arlokoak erabili dira: Pubmed, Dialnet Plus, Cochrane eta Cuiden. Biblioteca Virtual de la Salud metabilatzailea ere erabili da.

Horrez gain, informazio zabalagoaren bila, honako web-orriak ere kontsultatu dira:

- Asociación Española contra el Cáncer (AECC)

- American Society of Clinical Oncology (ASCO)

- National Cancer Institute (NCl)

- NNNConsult

Testuen aukeraketarako eta emaitza zehatzagoak izateko, hainbat barneratze- eta kanporatze-irizpide finkatu dira (Ikusi 2. taula).

2. taula. Barneratze- eta kanporatze-irizpideak.

\begin{tabular}{|c|c|}
\hline Barneratze-irizpideak & Kanporatze-irizpideak \\
\hline 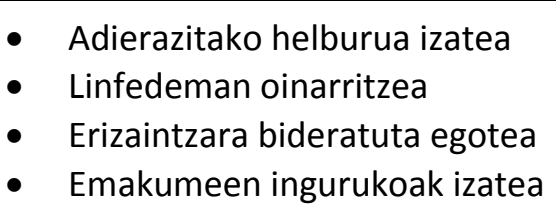 & $\begin{array}{l}\text { - } \quad \text { Lurralde geografiko batera mugatzea } \\
\text { - } \quad \text { Gai nagusitik aldentzea (linfedema) }\end{array}$ \\
\hline
\end{tabular}

Iturria: propioa.

Lehenago aipatutako datu-baseetan bilaketa egin ondoren, 48 artikulu topatu dira. Barneratze- eta kanporatze-irizpideak aplikatu ondoren, 17 artikulu aukeratu dira emaitzen garapenerako (Ikusi 3. taula). Artikulu horiek ebidentzia-mailaren arabera sailkatu dira ondoren (Ikusi 4. eranskina).Bilaketaren ondoren, artikuluak landu dira eta KASPEren fitxak erabili dira irakurketa kritikoa egiteko. Horrez gain, lortutako emaitzekin RB Haynes-en piramidearen araberako sailkapena egin da, artikuluak ebidentzia-mailaren arabera sailkatzeko. 
3. taula. Datu-baseetan egindako bilaketa bibliografikoaren emaitzak.

\begin{tabular}{|c|c|c|c|c|c|}
\hline Datu-basea & Gako-hitzak & $\begin{array}{l}\text { Artikulu } \\
\text { kopurua }\end{array}$ & Iragazkiak & $\begin{array}{l}\text { Artikulu } \\
\text { kopurua }\end{array}$ & $\begin{array}{c}\text { Hautatutako } \\
\text { artikuluak }\end{array}$ \\
\hline BVS & $\begin{array}{c}\text { Neoplasias de la mama } \\
\text { Linfedema } \\
\text { Enfermería } \\
\text { Calidad de vida }\end{array}$ & 18 & $\begin{array}{l}\text { - Inglés } \\
\text { - Español } \\
\text { - Últimos } 5 \\
\text { años }\end{array}$ & 4 & 3 \\
\hline DIALNET & $\begin{array}{c}\text { Neoplasias de la mama } \\
\text { Linfedema } \\
\text { Enfermería } \\
\text { Calidad de vida }\end{array}$ & 82 & $\begin{array}{l}\text { - Texto } \\
\text { completo } \\
\text { - Ciencias de } \\
\text { la salud } \\
\text { - 2010-2019 } \\
\text { - Español }\end{array}$ & 28 & 3 \\
\hline PUBMED & $\begin{array}{l}\text { Breast Neoplasms } \\
\text { Lymphedema } \\
\text { Nursing } \\
\text { Quality of life }\end{array}$ & 33 & $\begin{array}{l}\text { - } 5 \text { years } \\
\text { - Humans }\end{array}$ & 10 & 7 \\
\hline CUIDEN & $\begin{array}{c}\text { Neoplasias de la mama } \\
\text { Linfedema } \\
\text { Enfermería } \\
\text { Calidad de vida } \\
\end{array}$ & 3 & - 2014-2019 & 3 & 1 \\
\hline COCHRANE & $\begin{array}{c}\text { Breast Neoplasms } \\
\text { Lymphedema } \\
\text { Nursing } \\
\text { Quality of life }\end{array}$ & 5 & $\begin{array}{l}\text { - 2014-2019 } \\
\text { - Texto } \\
\text { completo }\end{array}$ & 3 & 3 \\
\hline
\end{tabular}

Iturria: propioa.

\section{Emaitzak}

\subsection{Eragina bizi-kalitatean}

Bizi-kalitateak ongizate fisikoa, psikologikoa, soziala eta espirituala hartzen ditu barne. Linfedema garatzen duten pazienteak bizi-kalitatea eta estatus funtzionala murrizteko arriskuan daude, desitxuratzea, deserosotasuna, ezintasuna eta eguneroko aktibitateak egiteko oztopoak eragiten dizkieten aldaketa fisikoen ondorioz(Alonso B, 2016; Burckhardt M, 2014; Cal A, 2016; Nadal MJ, 2015).

Erizaintzako Artatze Prozesua (EAP), praktika asistentzialean metodo zientifikoaren aplikazioan datza. Horrek, pazienteak era arrazionalean, logikoan eta sistematikoan zaintzea ahalbidetzen du. Horren harira, North American Nursing Diagnosis Association (NANDA) elkartearen taxonomia II oinarritzat hartuta, linfedemak hurrengo domeinuetan du eragina:

\section{4. domeinua: Ariketa fisikoa/atsedena}

Pazienteek zailtasunak adierazten dituzte lo egiteko garaian. Izan ere, zaila suerta daiteke posizio bera mantentzea, edo erasandako besoa libre mantentzea. Zeinuen eta sintomen ondorioz, besoaren mugimenduak mugatuta daude (sorbaldaren abdukzioa eta albo-errotazioa) eta zailtasunak topa ditzakete eguneroko jarduerak egiteko garaian. Mugapenek egun bakoitza erronka berri bat bilakatzen dute, sinplea zena konplikatu bilakatuz. Adibidez, ondo egokitzen den arropa bilatzea zaila 
izan daiteke. Horren guztiaren ondorioz, nekatuta sentitzea oso ohikoa da pazienteen artean (Alonso B, 2016; Boquiren V, 2016; Burckhardt M, 2014; Cal A, 2016).

\section{6. domeinua: Autopertzepzioa}

Euren itxura-aldaketa deskribatzerako garaian, itsusia, beldurgarria, handitua edo kaltetua bezalako hitzak erabiltzen dituzte pazienteek. Izan ere, hanturak edo azalean eman daitezkeen aldaketek eragin handia izan dezakete norberaren itxuraren pertzepzioan (Alonso B, 2016; Burckhardt M, 2014; Nadal MJ, 2015).

Gorputz-irudiaren aldaketak eta estres emozionalak ongizate psikologikoan eragina dutela ikusi da, baita autoestimuan ere (depresioa, antsietatea). Pazienteek linfedemaren inguruan duten pertzepzioa ere garrantzitsua da bizi-kalitate psikologiko eta sozialerako (Alonso B, 2016; Karlsson K, 2015; Ridner S, 2015).

Horrez gain, egunerokotasunean egin ohi zituzten ekintzak gauzatzeko zailtasunak topatzean, ezintasun-sentsazioak izan ditzakete pazienteek eta euren burua besteekin konparatu. Hala erakusten dute Ayse Cal eta Zuhal Bahar-en ikerketa kualitatiboan elkarrizketaturiko emakume baten hitzek:

"... Ez dut inoiz ezer egingo. Txotxongiloa edo printzesa izango banintz moduan jardungo naiz (barrez). Hala ere, hantura segituan agertzen da ariketa neketsuren bat egin ondoren". "Ezin ditut gauza sinpleak egin; ezin dut nire senarrak edo alabak egiten duena egin (Cal A, 2016)".

\section{7. domeinua: Rola/erlazioak}

Besteenganako dependentzia zuzenean lotuta dago linfedemaren intentsitatearekin. Pazienteak laguntza gehiago edo gutxiago beharko du eguneroko aktibitateak egiteko, adibidez, pisua jaso (Burckhardt M, 2014). Horrez gain, linfedemak eskatzen duenarretak denbora behar izaten dute. Ondorioz, zailtasunak izaten dituzte ama, etxeko andre, emazte edo lagun rolak aurrera eramateko, eta aurretik betetzen zituzten ekintzak eta ardurak beste pertsona batzuengan delegatu behar izaten dituzte sarritan (erosketa egitea, adibidez). Honela dio Jeffs eta lankideek haien ikerketan elkarrizketatutako emakume batek:

"Konpresio-arropa azkar janzten dut, baina besoko masajeek 10-15 minutu irauten dute, beste nonbaitetik atera behar ditudanak... (Jeffs E, 2015)".

Pazienteak beren erlazio pertsonaletan linfedemak izan dezakeen eraginagatik ere kezkatzen dira. Horren adibide dira kulpa-sentsazioa, edo lagunenganako eta senideenganako alienaziosentimenduak. Hori dela eta, aldaketak gertatu ohi dira haien bizitza sozialean (Burckhardt M, 2014).

\section{8. domeinua: Sexualitatea}

Bai erakargarritasunaren galerak eta horrek haien bizitza sexualean izan ditzakeen eraginek, bai gorputz-irudiaren aldaketak kezkatzen dituzte. Izan ere, gorputz-adarren hanturak pazientearen itxura aldatu dezake eta horrek aldi berean deserosotasuna eta konfiantza falta ekar ditzake, baita erakargarritasunaren galeraren pertzepzioa ere (Alonso B, 2016; Garcia SN, 2015; Gass J, 2016).

\section{9. domeinua: Estresaren tolerantzia}

Bularreko minbiziarekin erlazionatutako linfedema duten emakumeek dolu-sentimenduak izaten dituzte, galera-sentsazioa, beteta ez dauden desioak eta ziurgabetasuna. Linfedema dutela ohartzean, lehenengo sentsazioak tristura, haserrea eta frustrazioa izaten dira. Gainera, bizitza osorako izango duten konplikazio bat dela onartu behar dute, egunerokotasunean minbiziaren oroigarri izango dena. Ondorioz, etorkizunerako duten ikuspegia aldatu egin ohi da. Linfedema garatu aurretik zuten bizimoduaren eta normaltasun-sentsazioaren falta sumatzen dute. Horrez gain, 
beldurra sentitzea ohikoa izaten da sintomen eta horiek ekar ditzaketen konplikazioen aurrean, edo besoa galtzearekin erlazionatuta (Burckhardt M, 2014; Cal A, 2016; Garcia SN, 2015).

Antsietatea, beldurra edo ezinegona eragin ohi dituen beste faktore bat ekonomikoa da. Linfedemaren tratamenduak dakarrenkostu ekonomikoa iraunkorra da, arazo kronikoa baita. Ondorioz, horrek ekarriko duen karga pazienteak duen osasun-estalduraren araberakoa izango da (Alonso B, 2016; Burckhardt M, 2014; Karlsson K, 2015).

Horrez gain, linfedema pairatzen duten pazienteek lehendabizi minbizia gainditu behar izaten dute. Horren ondorioz, atentzioa minbizian zentratu eta linfedema bigarren maila batean geratu ohi da (Jeffs E, 2015). Horrek, antsietatea eta estresa eragin dezake pazienteengan, Karlsson et al.-en ikerketan emakume baten hitzetan islatzen den moduan:

"Uste dut informazioa falta dela orokorrean, badakizu hasieratik informatua izan behar duzula hau guztia zertan datzan ulertzeko, baina horren egoera garrantzitsuan edo minbizia duzunean, biziraun egin behar duzu eta linfedema bigarren maila batera igarotzen da. Ondoren, sendatzen zarenean oraindik linfedema daukazu baina denbora asko igaro da. Agian beranduegi da ezer egiteko (Karlsson K, 2015)".

\section{1. domeinua: Segurtasuna/babesa}

Lehenago aipatu den bezala, linfedemaren ondorioz erasandako besoan aldaketak jasaten dituzte larruazalean. Gainera, infekzioak izateko arriskua handia da paziente hauetan. Ondorioz, larruazalean lesioak izatea oso ohikoa da linfedema-kasuetan (AECC, 2018; De Miguel C, 2017; NCl, 2019).

\section{2. domeinua: Erosotasuna}

Erosotasunari eragiten dion faktore nagusia mina da (Alonso B, 2016). Linfedema garatu den besoa hanturaren ondorioz minduta izateaz gain, beste besoan ere senti daiteke. Izan ere, konplikazioa agertzen denetik karga handia jasan behar izaten du beste besoak. Hau islatuta agertzen da aurretik aipatutako Cal eta Bahar-en ikerketa kualitatiboan elkarrizketaturiko emakume baten hitzetan:

"Linfedema daukadanetik eta beste besoa erabili behar dudanetik, muskulu-distentsioa pairatu dut nire ezker sorbaldan. Dena beso batekin soilik egitea oso zaila suertatzen da (Cal A, 2016)".

Hainbat galdeketa existitzen dira pazienteek euren sintomak ebaluatzeko tresna gisa baliagarriak direnak, adibidez, Ridner et al.-ek eta Boquiren et al.-ek euren artikuluetan aipatutakoak (Boquiren $V$, 2016) (Ikusi 1. eranskina). Tresna horien bidez, linfedemak euren bizi-kalitatean duen inpaktua neur dezakete, bai eurek eta bai osasun-profesionalek ere.

\subsection{Erizaintza-interbentzioak}

Linfedemaren inguruan erizainon informazioa eta laguntza jasotzeko beharra erakutsi dute emakumeen \% 49k (Cal A, 2016). Pazienteen \% 18-28 ez da osasun-profesionalengana joan laguntza bila, eta hainbat ikerketaren arabera, linfedemaren inguruko ezagutza koherentea izanez gero, sarriagotan bilatuko litzateke laguntza hori. Izan ere, linfedemaren inguruko ezagutzak eta hezkuntza sanitarioak berebiziko garrantzia daukate, eta hori, erizainok eskain diezaiekegu (Nadal MJ, 2015).

Espainiatik kanpo egindako ikerketek erakutsi dute erizainek garrantzi handia dutela linfedemarentzat tratamendua jasotzen duten pazienteen ebaluazioan eta kondizio horren prebentzioan. Izan ere, gaur egun ez dagoenez linfedema senda daitekeen frogarik, prebentzio egokia ezinbestekoa da diagnostikoa eta tratamendua ekiditeko, eta hortaz, hori izango da erizainaren funtsezko papera.

Lehenik eta behin, bularreko minbizia duten pazienteen artean linfedema garatzeko arriskua dutenak identifikatzeko egiteko garrantzitsua betetzen dute erizainek. Izan ere, ikusi da interbentzio goiztiarreko protokoloek linfedema-intzidentzia murriztu dutela arrisku handiko pazienteetan, baita 
gorputz-adarraren bolumena, eta gainera, egoera aurreratuagoetarako progresioa ere (Burckhardt M, 2014; Jeffs E, 2015; Karlsson K, 2015; Stuiver MM, 2015).

Egokiena prebentzioa tratamenduaren aurretik hastea litzateke, pazienteari eta familiari linfedema izateko arriskuaren inguruan heziketa emanez. Heziketa hori jasotako pazienteek, prebentzio-neurri gehiago jartzen dituzte praktikan, linfedemaren zeinu eta sintoma gutxiago izan dituzte eta emaitza kognitibo eta jarrerazko emaitza hobeak izan dituzte (López RM, 2015). Gainera, pazienteak jasotako informazioaren inguruan duen asebetetze-maila hobetzen da, eta aldi berean pazientea prestatu egiten da erabaki egokiak hartzeko etorkizunean linfedema agertuko balitz (ASCO, 2020; NCl, 2019).

Ebakuntza aurretiko heziketaren parte da linfedemaren intzidentzia eta patogeniaren inguruan informazioa ematea. Pazienteek sistema linfatikoaren funtzionamendua azaltzen duen informazioa ere jaso beharko lukete, linfedema nola sortzen den ulertu, arrisku-faktoreak identifikatzen ikasi eta linfedema prebenitzeko ekintzak ezagutu. Ekintza horien artean daude adibidez $\mathrm{NCl}$ erakundeak proposatutako higiene-neurriak, gorputz-adarren posizio gomendagarriak eta gorputz-adarrean odola pilatzea ekiditeko neurriak (Ikusi 2. eranskina).

Ebakuntzaren ondoren, berriz, programa indibidualizatua aplikatu beharko litzateke, arriskuak murriztu, drainadura linfatikoa bultzatu eta konpresio-arropak erabiltzen irakatsi beharko zaie. Izan ere, azken horien erabilera bultzatzea gomendagarria da, gaitasun funtzionalez gain gorputz-irudia ere hobetzen baitute. Horrela, pazienteari linfedemaren maneiua ahalik eta ondoeneramaten irakats diezaiokete eta honek guztiak pazientearen estatus funtzionala eta bizi-kalitatea hobetu dezake (Burckhardt M, 2014).

Horrez gain, pazienteei identifikatu beharreko zeinu eta sintoma goiztiarrak zein diren azaldu beharko zaie: bitxiak estuago sentitzea, mina, pisu- edo astuntasun-sentsazioa, estutasuna, betetasun-sentsazioa, gogortasuna eta hantura (Burckhardt M, 2014; Jeffs E, 2015; Karlsson K, 2015).

Aldi berean, profesional aproposak koordinatzea eta pazienteei beren autozainketan duten garrantzia azpimarratzea ere erizainaren lana da. Izan ere, kontziente izan behar dute linfedema ez dela bularreko minbizia duen emakume baten kezka nagusia. Hala ere, ez zaio garrantzirik kendu behar eta arazo serio gisa artatua izan behar da, bereziki lehenengo zeinuen eta sintomen agerpenean. Gainera, frogatu da autozainketak eragin positiboak dituela pazientearen bizikalitatean(Burckhardt M, 2014; Karlsson K, 2015; Nadal MJ, 2015; Temur K, 2019).

Autozainketaren adibide izan daiteke pazienteek euren besoaren neurketak egitea, inpedantzia bioelektrikoaren bidez, adibidez, edo euren kabuz ariketak aurrera eramatea. Hala ere, pazienteek euren sintoma eta helburuetara egokitu ohi dute autozainketa-programa. Autozainketaren arrakastarako gakoa errutina dela azpimarratzen dute pazienteek, Jeffs et al.-en ikerketan: "Jantzi aurretik edo ezer egiten hasi aurretik nire ariketak egiten ditut eta goizaren errutinaren parte da. Horri esker, ez dut pentsatu beharrik, zuzenean egiten ditut. Horrek asko errazten dit bizitza (Jeffs E, 2015)".

Horrez gain, erizain gisa gainerako paziente kronikoen jarraipena egiten den moduan (adib. diabetikoak), paziente hauen jarraipena ere egin beharko litzateke. Izan ere, aurretik aipatu bezala, linfedema kronikoa da eta aldaketa ugari dakartza pazientearen egoera psikosozialean.

Hori kontuan izanik, aurretik aztertutako domeinuetan oinarrituz erizain-diagnostiko ezberdinak erlaziona daitezke linfedema pairatzen duten paziente hauekin. Aldi berean, hainbat erizaininterbentzio plantea daitezke (Ikusi 4. taula) (NNNConsult, 2015). Interbentzio espezifiko horiez gain, paziente guztiekin osasun-heziketa, entzute aktiboa eta jarraipen telefonikoa egin beharko lirateke. 
4. taula. Domeinuetan oinarritutako erizain-diagnostikoak eta interbentzioak.

\begin{tabular}{|c|c|c|c|}
\hline Domeinuak & Erizain-diagnostikoak & Helburuak & Erizain-interbentzioak \\
\hline \multirow{3}{*}{$\begin{array}{l}4 . \\
\text { domeinua: } \\
\text { Ariketa } \\
\text { fisikoa/ } \\
\text { Atsedena }\end{array}$} & $\begin{array}{l}00198 \text { Loaren } \\
\text { ereduaren } \\
\text { nahasmendua }\end{array}$ & 0003 Atsedena & $\begin{array}{l}1400 \text { Minaren maneiua } \\
1850 \text { Loa hobetzea } \\
6482 \text { Ingurunearen maneiua: } \\
\text { erosotasuna }\end{array}$ \\
\hline & $\begin{array}{l}00085 \text { Mugikortasun } \\
\text { fisikoaren narriadura }\end{array}$ & $\begin{array}{l}1811 \text { Ezagutza: } \\
\text { preskribatutako } \\
\text { ariketafisikoa }\end{array}$ & $\begin{array}{l}4310 \text { Aktibitate-terapia } \\
5612 \text { Hezkuntza: } \\
\text { aktibitatea/preskribatutako } \\
\text { ariketafisikoa }\end{array}$ \\
\hline & $\begin{array}{l}00109 \\
\text { Autozainketaren } \\
\text { porrota: } \\
\text { janztea/garbiketa }\end{array}$ & $\begin{array}{l}0300 \text { Norberaren } \\
\text { zainketak: } \\
\text { eguneroko jarduerak }\end{array}$ & $\begin{array}{l}1802 \text { Autozainketekin laguntza: } \\
\text { janztea/apaintzea }\end{array}$ \\
\hline \multirow{3}{*}{$\begin{array}{l}6 . \\
\text { domeinua: } \\
\text { Autoper- } \\
\text { tzepzioa }\end{array}$} & $\begin{array}{l}00152 \text { Inpotentzia- } \\
\text { arriskua }\end{array}$ & $\begin{array}{l}1302 \text { Arazoei aurre } \\
\text { egitea }\end{array}$ & $\begin{array}{l}4920 \text { Entzute aktiboa } \\
5270 \text { Sostengu emozionala } \\
5430 \text { Laguntza-taldea }\end{array}$ \\
\hline & $\begin{array}{l}00120 \text { Egoerarekin } \\
\text { erlazionatutako } \\
\text { autoestimu baxua }\end{array}$ & 1205 Autoestimua & $\begin{array}{l}5230 \text { Aurre egitea indartzea } \\
5250 \text { Hartutako erabakietan alde } \\
\text { agertzea } \\
5270 \text { Sostengu emozionala } \\
5400 \text { Autoestimuaren indartzea }\end{array}$ \\
\hline & $\begin{array}{l}00118 \text { Gorputz- } \\
\text { irudiaren } \\
\text { nahasmendua }\end{array}$ & 1200 Gorputz-irudia & $\begin{array}{l}4920 \text { Entzute aktiboa } \\
5220 \text { Gorputz-irudiaren indartzea } \\
5230 \text { Aurre egiteko gaitasuna } \\
\text { indartzea }\end{array}$ \\
\hline $\begin{array}{l}7 . \\
\text { domeinua: } \\
\text { Rola / } \\
\text { Erlazioak }\end{array}$ & $\begin{array}{l}\text { 00055 Rolaren betetze } \\
\text { ez eraginkorra } \\
\text { 00052 Interakzio } \\
\text { sozialaren narriadura }\end{array}$ & $\begin{array}{l}1305 \text { Egokitzapen } \\
\text { psikosoziala: bizitza- } \\
\text { aldaketa } \\
\begin{array}{l}1503 \text { Inplikazio } \\
\text { soziala }\end{array}\end{array}$ & $\begin{array}{l}4410 \text { Helburuak bateratzea } \\
5370 \text { Rolen indartzea } \\
5390 \text { Norberaren kontzientzia } \\
\text { indartzea } \\
5100 \text { Sozializazioa indartzea } \\
5230 \text { Aurre egiteko gaitasuna } \\
\text { indartzea } \\
5400 \text { Autoestimua indartzea }\end{array}$ \\
\hline $\begin{array}{l}8 . \\
\text { domeinua: } \\
\text { Sexualitatea }\end{array}$ & $\begin{array}{l}00065 \text { Eraginkorra ez } \\
\text { den sexu-patroia }\end{array}$ & 1205 Autoestimua & $\begin{array}{l}4920 \text { Entzute aktiboa } \\
5270 \text { Sostengu emozionala } \\
5400 \text { Autoestimuaren indartzea }\end{array}$ \\
\hline $\begin{array}{l}9 . \\
\text { domeinua: } \\
\text { Estresarekik } \\
\text { o tolerantzia }\end{array}$ & $\begin{array}{l}00148 \text { Beldurra } \\
00146 \text { Antsietatea } \\
00069 \text { Aurre egite ez- } \\
\text { eraginkorra }\end{array}$ & $\begin{array}{l}1300 \text { Osasun- } \\
\text { egoeraren onarpena } \\
1305 \text { Egokitzapen } \\
\text { psikosoziala: bizitza- } \\
\text { aldaketa }\end{array}$ & $\begin{array}{l}4920 \text { Entzute aktiboa } \\
5270 \text { Sostengu emozionala } \\
5290 \text { Dolua erraztea } \\
5440 \text { Laguntza-sistemak } \\
\text { areagotzea } \\
7380 \text { Baliabide ekonomikoetarako } \\
\text { laguntza }\end{array}$ \\
\hline
\end{tabular}




\begin{tabular}{|c|c|c|c|}
\hline & $\begin{array}{l}\text { 00177 Gainkargaren } \\
\text { ondoriozko estresa } \\
00136 \text { Dolua }\end{array}$ & $\begin{array}{l}1402 \text { Antsietatearen } \\
\text { kontrola }\end{array}$ & \\
\hline \multirow{2}{*}{$\begin{array}{l}\text { 11. } \\
\text { domeinua: } \\
\text { Segurtasuna } \\
\text { / Babesa }\end{array}$} & $\begin{array}{l}00004 \text { Infekzio- } \\
\text { arriskua }\end{array}$ & \multirow{2}{*}{$\begin{array}{l}1101 \text { Azalaren } \\
\text { osotasuna }\end{array}$} & \multirow{2}{*}{$\begin{array}{l}3590 \text { Larruazalaren zainketa } \\
5510 \text { Osasun-heziketa } \\
6550 \text { Infekzioen aurkako babesa } \\
6610 \text { Arriskuen identifikazioa }\end{array}$} \\
\hline & $\begin{array}{l}\text { 00047 Larruazalaren } \\
\text { osotasunaren } \\
\text { narriadura-arriskua }\end{array}$ & & \\
\hline $\begin{array}{l}12 . \\
\text { domeinua: } \\
\text { Erosotasuna }\end{array}$ & $\begin{array}{l}00133 \text { Min kronikoa } \\
00214 \text { Deserosotasuna }\end{array}$ & $\begin{array}{l}1605 \text { Minaren } \\
\text { kontrola }\end{array}$ & $\begin{array}{l}1400 \text { Minaren maneiua } \\
2395 \text { Medikazioaren kontrola } \\
4920 \text { Entzute aktiboa } \\
5230 \text { Aurre egiteko gaitasuna } \\
\text { indartzea }\end{array}$ \\
\hline
\end{tabular}

Iturria: propioa.

\section{Eztabaida}

Hainbat dira linfedemaren eta ariketa fisikoaren inguruan sortu diren eztabaidak. Zenbait ikerketakgomendatzen dute ebakuntzaren ondoren ahalik eta bizkorren sorbaldaren errehabilitazioariketak egiten hastea linfedema prebenitzeko asmoz. Izan ere, ariketa horiek lehenbailehen praktikatzen hasteak epe laburrean gorputz-adarraren mugimendu-maila handiagoa berreskuratzea ekar dezake, eta aldi berean pazientearen bizi-kalitatean eragin positiboa izan. Hori dela eta, sorbaldaren mugimenduari garrantzi handia ematen dioten osasun-profesionalek garrantzi bera emango diote errehabilitazio goiztiarrari (AECC, 2018; $\mathrm{NCl}, 2019)$.

Hala ere,Stuiver et al.-en berrikusketan, beste aukera bat aztertzen da: errehabilitazio-ariketa horiek astebete atzeratzea. Izan ere, errehabilitazio-ariketen hasiera goiztiarra edo berantiarra alderatzean eragin esanguratsurik frogatu ez den arren, linfedema garatzeko arrisku txikiagoa azter daiteke hasiera berantiarraren kasuan.

Bildutako datuen arabera, seromaren sorreraren intzidentzia murriztu ez arren, ebakuntzaren osteko sorbaldaren errehabilitazioaren atzerapenak zauriaren drainaduraren bolumena eta drainaduradenbora murrizten ditu (Stuiver MM, 2015). Ondorioz, errehabilitazio-ariketa hauen atzerapena balora daiteke pazientearen kasuaren arabera.

Horrez gain, aipatu beharrekoa da linfedemaren zainketen eta erizaintzaren inguruko informazio falta handia dagoela. Izan ere, dauden ikerketa gehienek linfedema bere baitan aztertzen dute eta ez erizaintzak berarekiko duen garrantzia. Gainera, horrek dakartzan konplikazioak tratatzeko edo baretzeko dauden terapien edo aukera desberdinen eraginkortasunaren inguruko ebidentzia-maila baxua da. 


\section{Ondorioak}

Goiko gorputz-adarretako linfedemak eragin handia du emakumeen eguneroko bizitzan. NANDA elkartearen taxonomia II oinarri hartuta, eragindako domeinu bakoitzeko erizain-diagnostiko eta interbentzio desberdinak eraman daitezke aurrera (Ikusi 4. taula).

Horrez gain, prebentzio egokia egitea ezinbestekoa da eta erizainak paper garrantzitsua betetzen du horretan, honako ekintza hauek aurrera eramanez: pazienteen identifikazio goiztiarra, osasunheziketa, profesionalen koordinazioa eta autozainketa eta konpresio-arropen erabileraren promozioa.

Ebidentzia-maila handiagoa beharko litzateke linfedema eta erizaintzari bideratuta, zainketa eta interbentzioak gehiago zehaztu ahal izateko.

\section{Bibliografia}

1. Alonso B. Cuestionario de calidad de vida ULL-27: un instrumento específico para pacientes con linfedema de miembro superior tras cáncer de mama [tesia]. Madrid: Universidad Complutense de Madrid; 2016. p. 17-35

2. American Society of Clinical Oncology (ASCO) [Internet]. Alexandria: ASCO; 2020 [kontsulta 22/11/2019]. Erabilgarri: https://asco.org

3. Asociación Española Contra el Cáncer (AECC) [Internet]. Madrid: AECC; 2018 [kontsulta 2019/11/16]. Erabilgarri: https://www.aecc.es/es

4. Boquiren VM, Hack TF, Thomas RL, Towers A, Kwan WB, Tilley A, Quinlan E, Miedema B. A longitudinal analysis of chronic arm morbidity following breast cancer surgery [Internet]. Breast Cancer Res Treat. 2016 [kontsulta 2019/12/02]; 157(3):413-25. Erabilgarri: https://link.springer.com/article/10.1007\%2Fs10549-016-3834-8

5. Bromham N, Schmidt-Hansen M, Astin M, Hasler E, W Reed M. Tratamiento axilar para el cáncer de mama primario operable [Internet]. Cochrane Database of Systematic Reviews. 2017 [kontsulta 2019/12/02]; Issue $1 . \quad$ Art. No.: CD004561. Erabilgarri: https://www.cochranelibrary.com/cdsr/doi/10.1002/14651858.CD004561.pub3/epdf/full

6. Burckhardt M, Belzner M, Berg A, Fleischer S. Living With Breast Cancer-Related Lymphedema: A Synthesis of Qualitative Research [Internet]. Oncol Nurs Forum . 2014 [kontsulta 2019/12/02]; 41(4):220-37. Erabilgarri: https://onf.ons.org/onf/41/4/living-breast-cancer-related-lymphedemasynthesis-qualitative-research

7. Cal A, Bahar Z. Women's Barriers to Prevention of Lymphedema After Breast Surgery and Home Care Needs: A Qualitative Study [Internet]. Cancer nursing. 2016 [kontsulta 2019/12/02]; 39(6):1725.

Erabilgarri: https://journals.Iww.com/cancernursingonline/Abstract/2016/11000/Women_s_Barriers_to_Preven tion_of_Lymphedema_After.13.aspx

8. De Miguel C. Incidencia de linfedema en cáncer de mama precoz. Diferencias entre biopsia selectiva de ganglio centinela y linfadenectomía [tesia]. Madrid: Universidad Complutense de Madrid; 2017. p. 43-64

9. Ezzo J, Manheimer E, McNeely ML, Howell DM, Weiss R, Johansson KI, Bao T, Bily L, Tuppo CM, Williams AF, Karadibak D. Drenaje linfático manual para el linfedema posterior al tratamiento del cáncer de mama [Internet]. Cochrane Database of Systematic Reviews. 2015 [kontsulta 2019/12/02]; Issue $5 . \quad$ Art. $\quad$ No.: $\quad$ CD003475. https://www.cochranelibrary.com/cdsr/doi/10.1002/14651858.CD003475.pub2/epdf/full 
10. Garcia SN, Jacowski M, Castro GC, Galdino C, Guimarães PRB, Kalinke LP. Quality of life domains affected in women with breast cancer [Internet]. Rev Gaúcha Enferm. 2015 [kontsulta 2019/12/02]; 36(2):89-96. Erabilgarri: http://www.scielo.br/pdf/rgenf/v36n2/1983-1447-rgenf-36-02-00089.pdf

11. Gass J, Dupree B, Pruthi S, Radford D, Wapnir I, Antoszewska R, Curtis A, Johnson N. Breast Cancer Survivorship: Why, What and When? [Internet]. Ann Surg Oncol. 2016 [kontsulta 2019/12/02]; 23(10):3162-3167. Erabilgarri: https://link.springer.com/article/10.1245\%2Fs10434016-5403-0

12. Greenlee H, DuPont-Reyes MJ, Balneaves LG, Carlson LE, Cohen MR, Deng G, Johnson JA, Mumber M, Seely D, Zick SM, Boyce LM, Tripathy D. Clinical practice guidelines on the evidencebased use of integrative therapies during and after breast cancer treatment [Internet]. CA Cancer J Clin. 2017 [kontsulta 2019/12/02]; 67(3):194-232. Erabilgarri: https://acsjournals.onlinelibrary.wiley.com/doi/full/10.3322/caac.21397

13. Jeffs $E$, Ream E, Shewbridge A, Cowan-Dickie S, Crawshaw D, Huit M, Wiseman T. Exploring patient perception of success and benefit in self-management of breast cancer-related arm lymphoedema [Internet]. Eur J Oncol Nurs. 2016 [kontsulta 2019/12/02]; 20:173-83.

Erabilgarri: https://www.ejoncologynursing.com/article/S1462-3889(15)30018-1/fulltext

14. Karlsson K, Biguet G, Johansson K, Nilsson-Wikmar L. Perceptions of lymphoedema treatment in patients with breast cancer - a patient perspective [Internet]. Scand J Caring Sci. 2015 [kontsulta 2019/12/02]; 29(1):110-7. Erabilgarri: https://onlinelibrary.wiley.com/doi/10.1111/scs.12138

15. López RM, Muriel C, López S. Tratamiento Fisioterápico del Linfedema en las pacientes tratadas de Cáncer de Mama [Internet]. Enferm Docente. 2015 [kontsulta 2019/12/02]; (103):55-9. Erabilgarri: http://www.huvv.es/servicioandaluzdesalud/huvv/sites/default/files/revistas/ED-103-13.pdf

16. Nadal MJ. Prevención del linfedema tras el vaciamiento axilar ganglionar en cáncer de mama [tesia]. Barcelona: Universitat Autònoma de Barcelona; 2015. p. 34-52

17. National Cancer Institute (NCl) [Internet]. Bethesda: NCl; 2019 [kontsulta 2019/11/07]. Erabilgarri: https://www.cancer.gov/

18. NNNConsult [Internet]. Barcelona: Elsevier; 2015 [kontsulta 2020/01/19]. Erabilgarri: https://www.nnnconsult.com/

19. Observatorio del cáncer Asociación Española Contra el Cáncer (AECC). Datos cáncer de mama 2019. Madrid: AECC; 2019. p. (1-5)

20. Organización Mundial de la Salud (OMS) [Internet]. Ginebra: OMS; 2019 [kontsulta 2019/11/09]. Erabilgarri: https://www.who.int/es

21. Ridner S, Dietrich M. Development and validation of the Lymphedema Symptom and Intensity Survey-Arm [Internet]. Support Care Cancer. 2015 [kontsulta 2019/12/02]; 23(10):3103-3112. Erabilgarri: https://link.springer.com/article/10.1007\%2Fs00520-015-2684-y

22. Stuiver MM, ten Tusscher MR, Agasi-Idenburg CS, Lucas C, Aaronson NK, Bossuyt PMM. Intervenciones conservadoras para la prevención del linfedema de miembro superior clínicamente detectable en pacientes que están en riesgo de desarrollar un linfedema después del tratamiento del cáncer de mama [Internet]. Cochrane Database of Systematic Reviews. 2015 [kontsulta 2019/12/02]; Issue $2.2 \quad$ Art. $\quad$ No.: $\quad$ CD009765. https://www.cochranelibrary.com/cdsr/doi/10.1002/14651858.CD009765.pub2/epdf/full

23. Temur K, Kapucu S. The effectiveness of lymphedema self-management in the prevention of breast cancer-related lymphedema and quality of life: A randomized controlled trial [Internet]. Eur J 
Oncol Nurs. 2019 [kontsulta 2019/12/02]; 40:22-35. Erabilgarri: https://www.ejoncologynursing.com/article/S1462-3889(19)30021-3/fulltext

\section{Eranskinak}

1. eranskina. Linfedemaren ebaluaziorako eta autozainketarako galdetegiak

\begin{tabular}{|c|c|c|}
\hline \multirow{7}{*}{$\begin{array}{l}\text { A Pilot Randomized } \\
\text { Trial Evaluating } \\
\text { Lymphedema Self- } \\
\text { Measurement with } \\
\text { Bioelectrical } \\
\text { Impedance, Self-Care } \\
\text { Adherence, and Health } \\
\text { Outcomes }\end{array}$} & $\begin{array}{l}\text { Lymphedema Symptom } \\
\text { Intensity and Distress Survey- } \\
\text { Arm (LSIDS-A) }\end{array}$ & $\begin{array}{l}\text { 36 item. } \\
\text { Sintomen } \\
\text { bai/ez. } \\
\text { Baiezkoen } \\
\text { puntuko kasuan } 10 \\
\text { eskala. }\end{array}$ \\
\hline & $\begin{array}{c}\text { Work Productivity and } \\
\text { Activity Impairement (WPAI) } \\
\text { Questionnaire }\end{array}$ & $\begin{array}{l}9 \text { item. } \\
\text { Eraginkortasun-orduen } \\
\text { galera eta aktibitate } \\
\text { murriztua. }\end{array}$ \\
\hline & $\begin{array}{l}\text { Upper Limb Lymphedema } \\
\text { (ULL-27) }\end{array}$ & $\begin{array}{l}27 \text { item. } \\
\text { Besoko linfedemaren bizi- } \\
\text { kalitatearen eskala } \\
\text { espezifikoa. }\end{array}$ \\
\hline & $\begin{array}{l}\text { Resource Utilization and } \\
\text { Economic Burden } \\
\text { Questionnaire (RUEBQ) }\end{array}$ & $\begin{array}{l}25 \text { item. } \\
\text { Linfedemaren } \\
\text { tratamenduaren kostuekin } \\
\text { erlazionatutako galdeketa } \\
\text { espezifikoa. }\end{array}$ \\
\hline & $\begin{array}{c}\text { Weekly lymphedema self-care } \\
\text { checklist }\end{array}$ & $\begin{array}{l}20 \text { item. } \\
\text { Autozainketaren } \\
\text { frekuentzia. }\end{array}$ \\
\hline & $\begin{array}{c}\text { Perceived Medical Condition } \\
\text { Self-Management Scale } \\
\text { (PMCSMS) }\end{array}$ & $\begin{array}{l}8 \text { item. } \\
\text { Autozainketarako } \\
\text { gaitasuna ebaluatzeko } \\
\text { galdeketa. }\end{array}$ \\
\hline & Skin assesment & $\begin{array}{l}20 \text { item. } \\
\text { Eragindako besoaren eta } \\
\text { beso osasuntsuaren } \\
\text { azalaren balorazioa. }\end{array}$ \\
\hline \multirow[t]{2}{*}{$\begin{array}{l}\text { A longitudinal analysis } \\
\text { of chronic arm } \\
\text { morbidity following } \\
\text { breast cancer surgery }\end{array}$} & $\begin{array}{l}\text { Profile of Mood States-Short } \\
\text { Form (POMS-SF) }\end{array}$ & $\begin{array}{l}37 \text { item. } \\
\text { Azken astean izandako } \\
\text { estrespsikologikoa } \\
\text { neurtzeko. }\end{array}$ \\
\hline & $\begin{array}{c}\text { Disabilities of Arm, Shoulder, } \\
\text { and Hand Questionnaire } \\
\text { (DASH) }\end{array}$ & $\begin{array}{l}5 \text { puntuko eskala. } \\
\text { Ezgaitasun-maila } \\
\text { neurtzeko. }\end{array}$ \\
\hline
\end{tabular}

Iturria: Propioa. 
2. eranskina.Linfedemaren prebentziorako neurriak

\begin{tabular}{|c|c|}
\hline & Ekintzak \\
\hline $\begin{array}{l}\text { Higienea: } \\
\text { Azalaren eta azkazalen } \\
\text { zainketa }\end{array}$ & $\begin{array}{l}\text { - Azala eta azkazalak garbi mantendu infekzioentzako } \\
\text { - } \text { aterik ez zabaltzeko. } \\
\text { - } \text { beharrazkak lerro zuzenean moztu. Podologoa kontsultatu } \\
\text { - Hidratanteak eta antibiotikodun kremak erabili azalean } \\
\text { ebakidura txikiak egitean (paperarekin, adibidez). } \\
\text { - Eguzkitako krema era gradualean erabili. } \\
\text { - Kotoizko mediak edo galtzerdiak erabili; oinak garbiak } \\
\text { eta lehorrak mantendu. } \\
\text { - Sukaldeko eta lorezaintzako eskularruak eta josteko } \\
\text { titarea erabili. } \\
\text { - Oinutsik ibiltzea ekidin. } \\
\text { - Odola ateratzea, txertoak eta zain barneko sueroak } \\
\text { - Tekidin eragindako besoan. } \\
\text { - Tenperaturak baloratzeko beste besoa erabili, } \\
\text { - Infekzio-zeinuei arretaz erreparatu (sukarra, hantura, } \\
\text { gorritasuna, mina eta beroa), eta medikuarekin } \\
\text { kontsultatu. }\end{array}$ \\
\hline Gorputz-adarren posizioa & $\begin{array}{l}\text { - Ahal den heinean, besoa igota mantendu, bihotzaren } \\
\text { mailan. } \\
\text { - Besoak presioak jasatea ekidin: } \\
\circ \text { Estutzen ez duten arropak eta bitxiak ipini. } \\
\circ \text { Poltsa beste besoan zintzilik eraman. }\end{array}$ \\
\hline $\begin{array}{l}\text { Nola ekidin odola pilatzea } \\
\text { eragindako } \\
\text { adarrean }\end{array}$ & $\begin{array}{l}\text { - Gorputzeko zati distaletan likidoen pilatzea eragiten } \\
\text { duten mugimendu zirkularrak ekidin. } \\
\text { - Besoan beroa aplikatzea ekidin, odol-fluxua areagotu } \\
\text { dezake. } \\
\text { - Besoa grabitatearen menpe dagoen posizioak denbora } \\
\text { luzez mantentzea ekidin. } \\
\text { - Presioa neurtzeko zorroak edo arropa estuak ekidin, } \\
\text { tornikete-efektua izan dezakete. }\end{array}$ \\
\hline
\end{tabular}

Iturria:Nacional Cancer Institute (NCI). 
3. eranskina. Linfedemaren prebentziorako ariketak

\begin{tabular}{|c|c|c|}
\hline Arnas ariketak & Fluxu linfatikoa lagundu & Linfedema prebenitu \\
\hline $\begin{array}{l}\text { Diafragmatikoak: Arnasa } \\
\text { sudurretik hartu sabela } \\
\text { puztuz, airea barnean } \\
\text { mantendu eta pixkanaka } \\
\text { ahotik askatu. Eskuak } \\
\text { sabelean kokatu. }\end{array}$ & $\begin{array}{l}\text { Aulki batean eserita besoa } \\
\text { aurrerantz altxa eskua itxiz } \\
\text { eta irekiz. }\end{array}$ & $\begin{array}{l}\text { Makil bat horizontalki hartu } \\
\text { eta ahalik eta gehien altxa. }\end{array}$ \\
\hline $\begin{array}{l}\text { Toraziko baxuak: Airea } \\
\text { hartu toraxaren beheko } \\
\text { aldea zabalduz, ondoren } \\
\text { ahotik pixkanaka askatu. } \\
\text { Eskuak azken saihetsen } \\
\text { gainean kokatu. }\end{array}$ & $\begin{array}{l}\text { Posizio berean besoa lateralki } \\
\text { banandu eskua itxiz eta } \\
\text { irekiz. }\end{array}$ & $\begin{array}{l}\text { Besoak gurutzatu eta altxa } \\
\text { bi eskuak elkartuz. }\end{array}$ \\
\hline \multirow[t]{6}{*}{$\begin{array}{l}\text { Toraziko altuak: Airea } \\
\text { hartu toraxaren goiko } \\
\text { aldea zabalduz, ondoren } \\
\text { poliki ahotik askatu. } \\
\text { Eskuak toraxaren goiko } \\
\text { aldean kokatu. }\end{array}$} & $\begin{array}{l}\text { Mahai baten aurrean, } \\
\text { enborra zuzen, ipini eskua } \\
\text { liburu baten gainean. } \\
\text { Labaindu liburua aurrerantz } \\
\text { molestia bat sentitu arte. } \\
\text { Aurreko posiziora itzuli. }\end{array}$ & $\begin{array}{l}\text { Garondoan ipini bi eskuak } \\
\text { lotuta, eta ukondoak } \\
\text { elkartu eta banatu. }\end{array}$ \\
\hline & $\begin{array}{l}\text { Mahai baten alboan, mugitu } \\
\text { besoa aurrera eta atzera } \\
\text { liburu bat eskuaren azpian } \\
\text { ipinita. }\end{array}$ & $\begin{array}{l}\text { Bizkar atzean ipini bi eskuak } \\
\text { lotuta eta besoak atzera } \\
\text { eraman. }\end{array}$ \\
\hline & \multirow[t]{4}{*}{$\begin{array}{l}\text { Aulki batean eserita, toalla } \\
\text { bat eutsi bizkar atzetik. Esku } \\
\text { bat goitik eta bestea behetik } \\
\text { ipinita, mugimenduak } \\
\text { gauzatu bi eskuen } \\
\text { norabidean. }\end{array}$} & $\begin{array}{l}\text { Pareta baten aurrean ipini. } \\
\text { Kaltetutako besoarekin } \\
\text { zirkunferentzia bat } \\
\text { marraztu, ahalik eta } \\
\text { handiena, bi noranzkoetan. }\end{array}$ \\
\hline & & $\begin{array}{l}\text { Posizio berean, bigarren eta } \\
\text { hirugarren hatzak ahalik eta } \\
\text { goren eraman. }\end{array}$ \\
\hline & & $\begin{array}{l}\text { Besoak aurrera luzatuta, } \\
\text { sorbalden garaieran, ukon- } \\
\text { doa tolestu eta eskua itxi } \\
\text { aldi berean. }\end{array}$ \\
\hline & & $\begin{array}{l}\text { Besoak "braza" estiloan } \\
\text { igeri egingo bazenu bezala } \\
\text { mugitu. }\end{array}$ \\
\hline
\end{tabular}

Iturria: Asociación Española Contra el Cáncer (AECC). 
4. eranskina. Linfedemaren prebentziorako ariketak.

\begin{tabular}{|c|c|c|}
\hline IZENBURUA & URTEA & ARTIKULU MOTA \\
\hline $\begin{array}{l}\text { Tratamiento axilar para el cáncer de mama primario } \\
\text { operable (Revisión) }\end{array}$ & 2019 & $\begin{array}{c}\text { Errebisio } \\
\text { sistematikoa }\end{array}$ \\
\hline $\begin{array}{l}\text { Clinical practice guidelines on the evidence-based use of } \\
\text { integrative therapies during and following breast cancer } \\
\text { treatment }\end{array}$ & 2018 & $\begin{array}{c}\text { Errebisio } \\
\text { sistematikoa }\end{array}$ \\
\hline $\begin{array}{l}\text { Tratamiento Fisioterápico del Linfedema en las } \\
\text { pacientes tratadas de Cáncer de Mama }\end{array}$ & 2015 & $\begin{array}{c}\text { Errebisio } \\
\text { sistematikoa }\end{array}$ \\
\hline $\begin{array}{l}\text { Drenaje linfático manual para el linfedema posterior al } \\
\text { tratamiento del cáncer de mama (Revisión) }\end{array}$ & 2015 & $\begin{array}{c}\text { Errebisio } \\
\text { sistematikoa }\end{array}$ \\
\hline $\begin{array}{l}\text { Intervenciones conservadoras para la prevención del } \\
\text { linfedema de miembro superior clínicamente detectable } \\
\text { en pacientes que están en riesgo de desarrollar un } \\
\text { linfedema después del tratamiento del cáncer de mama } \\
\text { (Revisión) }\end{array}$ & 2015 & $\begin{array}{l}\text { Errebisio } \\
\text { sistematikoa }\end{array}$ \\
\hline $\begin{array}{l}\text { Living With Breast Cancer-Related Lymphedema: A } \\
\text { synthesis of Qualitative Research }\end{array}$ & 2014 & $\begin{array}{l}\text { Errebisio } \\
\text { sistematikoa }\end{array}$ \\
\hline $\begin{array}{l}\text { The effectiveness of lymphedema self-management in } \\
\text { the prevention of breast cancer-related lymphedema } \\
\text { and quality of life: A randomized controlled tria }\end{array}$ & 2019 & Entsegu klinikoa \\
\hline $\begin{array}{l}\text { Development and Validation of the Lymphedema } \\
\text { Symptom and Intensity Survey-Arm }\end{array}$ & 2015 & Entsegu klinikoa \\
\hline $\begin{array}{l}\text { A longitudinal analysis of chronic arm morbidity } \\
\text { following breast cancer surgery }\end{array}$ & 2016 & Kohorte-ikerketa \\
\hline $\begin{array}{l}\text { Quality of life domains affected in women with breast } \\
\text { cancer }\end{array}$ & 2015 & Kohorte-ikerketa \\
\hline Breast Cancer Survivorship: Why, What and When? & 2016 & $\begin{array}{l}\text { Errebisio } \\
\text { narratiboa }\end{array}$ \\
\hline $\begin{array}{l}\text { Women's Barriers to Prevention of Lymphedema After } \\
\text { Breast Surgery and Home Care Needs: A Qualitative } \\
\text { Study }\end{array}$ & 2016 & $\begin{array}{c}\text { Ikerketa } \\
\text { kualitatibo } \\
\text { deskriptiboa }\end{array}$ \\
\hline $\begin{array}{l}\text { Exploring patient perception of success and benefit in } \\
\text { self-management of breast cancer-related arm } \\
\text { lymphoedema }\end{array}$ & 2016 & $\begin{array}{c}\text { Ikerketa } \\
\text { kualitatibo } \\
\text { deskriptiboa }\end{array}$ \\
\hline $\begin{array}{l}\text { Perceptions of lymphoedema treatment in patients with } \\
\text { breast cancer - A patient prespective }\end{array}$ & 2015 & $\begin{array}{c}\text { Ikerketa } \\
\text { kualitatibo } \\
\text { deskriptiboa }\end{array}$ \\
\hline $\begin{array}{l}\text { Cuestionario de calidad de vida ULL-27: un instrumento } \\
\text { específico para pacientes con linfedema de miembro } \\
\text { superior tras cáncer de mama }\end{array}$ & 2016 & Tesia \\
\hline $\begin{array}{l}\text { Incidencia de linfedema en cáncer de mama precoz. } \\
\text { Diferencias entre biopsia selectiva de ganglio centinela y } \\
\text { linfadenectomía }\end{array}$ & 2017 & Tesia \\
\hline $\begin{array}{l}\text { Prevención del linfedema tras el vaciamiento axilar } \\
\text { ganglionar en cáncer de mama }\end{array}$ & 2015 & Tesia \\
\hline
\end{tabular}

Iturria: Propioa. 